\title{
Combination Radioimmunotherapy Approaches and Quantification of Immuno-PET
}

\author{
Jin Su Kim ${ }^{1,2,3}$
}

Received: 27 October 2015 / Revised: 18 December 2015 / Accepted: 23 December 2015 /Published online: 26 January 2016

(C) The Author(s) 2016. This article is published with open access at Springerlink.com

\begin{abstract}
Monoclonal antibodies (mAbs), which play a prominent role in cancer therapy, can interact with specific antigens on cancer cells, thereby enhancing the patient's immune response via various mechanisms, or mAbs can act against cell growth factors and, thereby, arrest the proliferation of tumor cells. Radionuclide-labeled mAbs, which are used in radioimmunotherapy (RIT), are effective for cancer treatment because tumor associated-mAbs linked to cytotoxic radionuclides can selectively bind to tumor antigens and release targeted cytotoxic radiation. Immunological positron emission tomography (immuno-PET), which is the combination of PET with $\mathrm{mAb}$, is an attractive option for improving tumor detection and $\mathrm{mAb}$ quantification. However, RIT remains a challenge because of the limited delivery of $\mathrm{mAb}$ into tumors. The transport and uptake of mAb into tumors is slow and heterogeneous. The tumor microenvironment contributed to the limited delivery of the mAb. During the delivery process of $\mathrm{mAb}$ to tumor, mechanical drug resistance such as collagen distribution or physiological drug resistance such as high intestinal pressure or absence of lymphatic vessel would be the limited factor of $\mathrm{mAb}$ delivery to the tumor at a potentially lethal $\mathrm{mAb}$ concentration. When $\alpha$-emitter-labeled mAbs were used, deeper penetration of $\alpha$-emitter-labeled $\mathrm{mAb}$ inside tumors
\end{abstract}

Jin Su Kim

kjs@kirams.re.kr

1 Molecular Imaging Research Center, Korea Institute of Radiological and Medical Sciences, 75 Nowon-Gil, Gongneung-Dong, Nowon-Gu, Seoul 01812, Korea

2 Korea Drug Development Platform using Radio-Isotope(KDePRI), Seoul, Korea

3 Radiologcial and Medico-Oncological Sciences, University of Science and Technology (UST), Seoul, Korea was more important because of the short range of the $\alpha$ emitter. Therefore, combination therapy strategies aimed at improving $\mathrm{mAb}$ tumor penetration and accumulation would be beneficial for maximizing their therapeutic efficacy against solid tumors.

Keywords Monoclonal antibody $\cdot$ Radioimmunotherapy · Immuno-PET · Tumor microenvironment

\section{Introduction}

Monoclonal antibodies (mAbs), which play a prominent role in cancer therapy, can interact with specific antigens on cancer cells, thereby enhancing the patient's immune response via various mechanisms, or mAbs can act against cell growth factors and, thereby, arrest the proliferation of tumor cells. Radionuclide-labeled mAbs, which are used in radioimmunotherapy (RIT), are effective for cancer treatment because tumor associated-mAbs linked to cytotoxic radionuclides can selectively bind to tumor antigens and release targeted cytotoxic radiation [1-3]. Iodine-131 ( $\left.{ }^{131} \mathrm{I}\right)$-labeled mAbs has been widely used in the successful treatment of patients with lymphoma in nuclear medicine [4-6]. Recently, $\alpha$-emitter-labeled RIT is considered a promising therapeutic strategy, because $\alpha$ emitters provide high linear energy transfer to tumors within a short range [7].

Although the concept of RIT may appear straightforward, in practice it has been difficult to achieve substantial clinical success, particularly in solid tumors due to the limited delivery of $\mathrm{mAb}$ into tumor $[8,9]$. Furthermore, limited delivery of $\mathrm{mAb}$ would be more problematic in therapy when $\alpha$-emitterlabeled RIT was performed because of the short range of $\alpha$ particles. In this paper, delivery strategies for $\mathrm{mAb}$ in RIT, and the imaging characteristics of some currently and widely used 
radioisotopes such as iodine-124 $\left({ }^{124} \mathrm{I}\right)$, zirconium-89 $\left({ }^{89} \mathrm{Zr}\right)$, and copper-64 $\left({ }^{64} \mathrm{Cu}\right)$ are discussed. Macro-level and microcellular-level dosimetry strategies are also described.

\section{Immuno-PET}

Immunological positron emission tomography (immunoPET), which is the combination of PET with $\mathrm{mAb}$, is an attractive option for improving tumor detection and $\mathrm{mAb}$ quantification. Immuno-PET has advantages over conventional radioimmunoscintigraphy in terms of accurate quantification of the $\mathrm{mAb}$ from the images $[10,11]$. The radioisotopes most often used for immuno-PET are: ${ }^{64} \mathrm{Cu}$ (half-life $\left[\mathrm{t}_{1 / 2}\right], 12.7 \mathrm{~h}$ ), and ${ }^{124} \mathrm{I}\left(\mathrm{t}_{1 / 2}, 4.2\right.$ days) [12]. Although ${ }^{64} \mathrm{Cu}$ was widely used for the clinical imaging of $\mathrm{mAb}[13,14], \mathrm{t}_{1 / 2}$ of ${ }^{64} \mathrm{Cu}$ is too short to prove effective with the slow pharmacokinetic profile of $\mathrm{mAb}$ in humans. The accumulation of $\mathrm{mAb}$ in tumors is a slow process, as is their clearance from the blood $\left(t_{1 / 2}, 50\right.$ $90 \mathrm{~h}$ ) [10]. Slow process of mAb delivery to tumor was due to limited transport of $\mathrm{mAb}$, which was described in the "limited transport of mAb to tumor" section in detail. Table 1 shows the physical characteristics of ${ }^{89} \mathrm{Zr},{ }^{124} \mathrm{I}$ and ${ }^{18} \mathrm{~F}$. PET radionuclides with a relatively long $t_{1 / 2}$, such as ${ }^{124} I\left(t_{1 / 2}, 4.2\right.$ days $)$ and ${ }^{89} \mathrm{Zr}\left(\mathrm{t}_{1 / 2}, 78.41 \mathrm{~h}\right)$, would be more suitable for immunoPET than those with a short $t_{1 / 2}$.

${ }^{124}$ I has been used for immuno-PET, but its imaging characteristics are limited in terms of spatial resolution and image quality. In addition, in vivo dehalogenation of ${ }^{124} \mathrm{I}$ is the main limiting factor [15]. The spatial resolution of ${ }^{124} \mathrm{I}$ is poorer than that of ${ }^{18} \mathrm{~F}$, because it has a longer $\beta^{+}$range than that of ${ }^{18} \mathrm{~F}\left(\beta^{+}\right.$range in water, 3.8 and $0.66 \mathrm{~mm}$ for ${ }^{124} \mathrm{I}$ and ${ }^{18} \mathrm{~F}$, respectively). Jin Su Kim's group in Korea Institute of Radiological and Medical Sciences (KIRAMS) reported that the spatial resolution of ${ }^{124}$ I was reduced by $19 \%$ compared with that of ${ }^{18} \mathrm{~F}$ on the ECAT HR+ scanner. The PET image quality with this radionuclide is poor owing to the cascade of $\gamma$ photons and low $\beta^{+}$branching ratio $\left(\beta^{+}\right.$branching ratio of ${ }^{124}$ I, $\left.23 \%\right)[16,17]$. High-energy $\gamma$ photons $(602,723$, and $1691 \mathrm{keV})$ are emitted in a cascade with the $\beta^{+}$The major interference is caused by $\gamma$ photons with energy levels of $602 \mathrm{keV}$ because their energy level falls within the standard energy window of most PET scanners, which will detect these photons as additional background noise or interference. In addition, the $602-\mathrm{keV} \gamma$ photons have a high branching ratio of approximately $61 \%$ and, as a result, the dead time of the system is also increased, while its count-rate performance is reduced [16]. Cascade $\gamma$ photons contribute to background image noise in ${ }^{124}$ I-PET and, therefore, this background interference must be corrected to improve the image quality. Moreover, Preylowski et al. [16] reported that the image quality could be improved after correcting the background noise caused by the higher energy $\gamma$ photons $(602$ and $732 \mathrm{keV})$. The correction of higher energy of $\gamma$ photons referred to as "prompt $\gamma$ correction" in the study by Preylowski et al. [16], was implemented in the Siemens Biograph mCT scanner. Preylowski et al.'s algorithm calculated the distribution of prompt coincidence using the convolution prompt $\gamma$ kernel with attenuation correction, and for random coincidences it also corrects acquired data. Kim's group developed a prompt $\gamma$ correction method for ${ }^{124}$ I-PET in a sinogram space [18]. The fraction of prompt $\gamma$ was derived using comparison of $\beta^{+}$ branching ratio corrected sensitivity. Briefly, the difference between branching ratio corrected sensitivity of ${ }^{124} \mathrm{I}$ and that of ${ }^{18} \mathrm{~F}$ was a fraction of prompt $\gamma$ [18]. According to the result, the single $\gamma$ fraction was $3 \%$ for $350-550 \mathrm{keV}, 24 \%$ for 350 $650 \mathrm{keV}$, and $31 \%$ for $350-750 \mathrm{keV}$. The higher single $\gamma$ fraction for a wider energy window was due to greater inclusion of $602-\mathrm{keV} \gamma$ within the energy window. Therefore, background noise count due to higher energy of $\gamma$ photons would differ from energy window width. According to the Jin $\mathrm{Su}$ Kim's method, "scatter distribution $\times$ single $\gamma$ photon fraction" is the portion of background count due to higher single $\gamma$ photon which could be calculated using the obtained scatter sinogram and measured branching ratio corrected sensitivity [18]. Recently, Jin Su Kim's group compared the effect of different filter and reconstruction methods for ${ }^{124}$ I quantification on Siemens Inveon PET scanner [19, 20].

${ }^{89} \mathrm{Zr}\left(\mathrm{t}_{1 / 2}, 78.41 \mathrm{~h}\right)$ is also an ideal radioisotope for immunoPET [21-23]. However, ${ }^{89} \mathrm{Zr}$ has also poor imaging characteristics because of low spatial resolution and image quality. Jin Su Kim's group in KIRAMS, Korea, reported that the spatial resolution of ${ }^{89} \mathrm{Zr}$ was approximately $9 \%$ lower than that of
Table 1 Physical characteristics of ${ }^{89} \mathrm{Zr},{ }^{124} \mathrm{I}$ and ${ }^{18} \mathrm{~F}$

\begin{tabular}{llll}
\hline Properties & ${ }^{89} \mathrm{Zr}$ & ${ }^{124} \mathrm{I}$ & ${ }^{18} \mathrm{~F}$ \\
\hline Half-life & $78.4 \mathrm{~h}$ & $4.18 \mathrm{day}$ & $109.8 \mathrm{~min}$ \\
Mean $\beta^{+}$energy & $0.40 \mathrm{MeV}$ & $0.83 \mathrm{MeV}$ & $0.25 \mathrm{MeV}$ \\
Mean $\beta^{+}$range in water & $1.23 \mathrm{~mm}$ & $3.48 \mathrm{~mm}$ & $0.62 \mathrm{~mm}$ \\
Single $\gamma$ energy & $909 \mathrm{keV}(99.9 \%)$ & $602 \mathrm{keV}(61 \%)$ & \\
& $1,657 \mathrm{keV}(0.1 \%)$ & $723 \mathrm{keV}(10 \%)$ & \\
$\beta^{+}$branching ratio & $1,713 \mathrm{keV}(0.8 \%)$ & $1,691 \mathrm{keV}(11 \%)$ & $97 \%$ \\
\hline
\end{tabular}


${ }^{18} \mathrm{~F}$ was using the Siemens Biograph Truepoint TrueV scanner (4.5 and $4.1 \mathrm{~mm}$ for ${ }^{89} \mathrm{Zr}$ and ${ }^{18} \mathrm{~F}$, respectively) [24]. The predicted spatial resolution of ${ }^{124} \mathrm{I}$ was $5.5 \mathrm{~mm}$ on the Siemens Biograph Truepoint TrueV scanner [24]. The value of the $\beta^{+}$range was $1.23,0.62$, and $1.23 \mathrm{~mm}$ for ${ }^{89} \mathrm{Zr},{ }^{18} \mathrm{~F}$, and ${ }^{124} \mathrm{I}$, respectively. The low spatial resolutions of ${ }^{89} \mathrm{Zr}$ and ${ }^{124} \mathrm{I}$ were due to their long $\beta^{+}$ranges. The degradation of the spatial resolution was also observed with animal dedicated PET scanners. According to the report by Disselhorst's group, the spatial resolution of ${ }^{89} \mathrm{Zr}$ was degraded by $10 \%$ compared with that of ${ }^{18} \mathrm{~F}$ on the Siemens Inveon PET scanner (1.99 and $1.81 \mathrm{~mm}$ for ${ }^{89} \mathrm{Zr}$ and ${ }^{18} \mathrm{~F}$, respectively) [25]. The $\beta^{+}$ branching ratio of ${ }^{89} \mathrm{Zr}$ was $23 \%$, which is lower than that of ${ }^{18} \mathrm{~F}$, but similar to that of ${ }^{124} \mathrm{I}$. Furthermore, the low $\beta^{+}$ branching ratio of ${ }^{89} \mathrm{Zr}$ degraded the image quality compared with that of ${ }^{18} \mathrm{~F}$ [24]. Figure 1 shows the transaxial images of the National Electrical Manufacturers Association (NEMA) IEC phantom for the comparison of image quality between ${ }^{89} \mathrm{Zr}$ and ${ }^{18} \mathrm{~F}$. In addition, ${ }^{89} \mathrm{Zr}$ emitted $909 \mathrm{keV}$ of $\gamma$ photons, which falls outside the energy window of clinical PET scanners, but the associated higher energy is still likely to cause Compton scattering. Furthermore, there was the possibility that the scattered photons would be included within the energy window, and produce some degree of noise [24]. Another problem associated with the $909-\mathrm{keV}$ energy of $\gamma$ photons was the radiation hazard, which was crucial for internal dosimetry and required the necessary provision of radiation protection for both patients and workers. Although there were limitations such as poor spatial resolution and image quality of the immuno-PET when ${ }^{89} \mathrm{Zr}$ or ${ }^{124} \mathrm{I}$ was used, they were a suitable match for the $t_{1 / 2}$ of the $m A b$ and, therefore, could provide a tool for monitoring the targeting of $\mathrm{mAb}$ to tumors.

\section{Radioimmunotherapy}

RIT such as those using ${ }^{131}$ I tositumomab (Bexxar; GlaxoSmithKline, Philadelphia,PA, USA) $[26-28],{ }^{90} \mathrm{Y}$ ibritumomabtiuxetan (Zevalin; Biogen Idec, Cambridge, MA, USA) $[29,30]$ and ${ }^{131}$ I rituximab (Rituxan; Genentech,
South San Francisco, CA, USA) were used for the treatment of hematological tumors. Recently, ${ }^{131}$ I tositumomab was withdrawn for commercial reasons [31]. Regarding RIT for solid tumors, trastuzumab (Herceptin; F. Hoffmann-La Roche, Basel, Switzerland), cetuximab (Erbitux; ImClone Systems, New York, USA), bevacizumab (Avastin; Genentech, South San Francisco, CA, USA) and panitumumab (Vectibix; Amgen, Taos, NM, USA) were used for the treatment.

For the RIT, lutetium-177 $\left({ }^{177} \mathrm{Lu}\right)\left(\mathrm{t}_{1 / 2}, 6.7\right.$ days; $\mathrm{E}_{\max }$, $497 \mathrm{keV}$; range max $_{\max }$ in water, $\left.2.1 \mathrm{~mm}\right)$, yttrium-90 $\left({ }^{90} \mathrm{Y}\right)\left(\mathrm{t}_{1 / 2}\right.$, 2.7 days; $\mathrm{E}_{\max }, 2,270 \mathrm{keV}$; range max $_{\text {max }}$ in water, $12.0 \mathrm{~mm}$ ), and ${ }^{131} \mathrm{I}_{\left(\mathrm{t}_{1 / 2}, 8\right.}, 8$ days, $\mathrm{E}_{\max }, 606 \mathrm{keV}$, range $\mathrm{max}_{\max }$ in water, $\left.2.4 \mathrm{~mm}\right)$ were used. ${ }^{90} \mathrm{Y}$ is a pure $\beta$ emitter, which requires a $\gamma$-emitting surrogate $\left({ }^{111} \mathrm{In}\right)$ for clinical imaging [32]. Glatting et al. [33] and Lhommel et al. [34] reported the feasibility of ${ }^{90} \mathrm{Y}$ as a PET radionuclide. However, because, the abundance of $\beta^{+}$ level of ${ }^{90} \mathrm{Y}$ was extremely low $(0.003 \%)$, and Bremsstrahlung photons were emitted during the PET acquisition [35], PET imaging with ${ }^{90} \mathrm{Y}$ was possibly due to inclusion of Bremsstrahlung photons during PET acquisition. The ${ }^{90} \mathrm{Y}$ particle has higher energy and longer particle range, leading to more radioactivity in the tumor cell per peptide molecule and superior crossfire through the tumor, which is especially advantageous in large tumors and tumors with heterogeneous receptor distribution. Furthermore, ${ }^{177} \mathrm{Lu}$ particles have lower energy and smaller particle range than ${ }^{90} \mathrm{Y}$ does, leading to better absorption in small tumors [32, 36, 37]. Frost et al. [32] showed that the mean absorbed dose of ${ }^{177} \mathrm{Lu}$ by the tumor was more than twofold higher than that for ${ }^{90} \mathrm{Y}$ following the administration of the same level of radioactivity.

The use of auger electrons [38-40] or $\alpha$ particles was feasible owing to the high linear energy transfer radiation within a short range. Alpha particles such as astatine-211 $\left({ }^{211} \mathrm{At}\right)\left(\mathrm{t}_{1 / 2}\right.$, $7.2 \mathrm{~h})$, bismuth-213 $\left({ }^{213} \mathrm{Bi}\right)\left(\mathrm{t}_{1 / 2}, 46 \mathrm{~min}\right)$, actinium-225 $\left({ }^{225} \mathrm{Ac}\right)\left(\mathrm{t}_{1 / 2}, 10\right.$ days $)$, bismuth-212 $\left({ }^{212} \mathrm{Bi}\right)\left(\mathrm{t}_{1 / 2}, 60 \mathrm{~min}\right)$, radium-233 $\left({ }^{233} \mathrm{Ra}\right)\left(\mathrm{t}_{1 / 2}, 11\right.$ days), terbium-149 $\left({ }^{149} \mathrm{~Tb}\right)\left(\mathrm{t}_{1 / 2}\right.$, $4 \mathrm{~h})$, and fermium-255 $\left({ }^{255} \mathrm{Fm}\right)\left(\mathrm{t}_{1 / 2}, 20 \mathrm{~h}\right)$ [41-45] would be possible for RIT. ${ }^{211} \mathrm{At}$ is of particular interest because of its high linear energy transfer (5,869 and 7,450 $\mathrm{MeV} \alpha$ particles),
Fig. 1 Transaxial images of NEMA IEC phantom using (a)

${ }^{89} \mathrm{Zr}$ images and $(\mathbf{b}){ }^{18} \mathrm{~F}$. Images were reconstructed using FBP.

This figure is reprinted from Lee et al. [24]
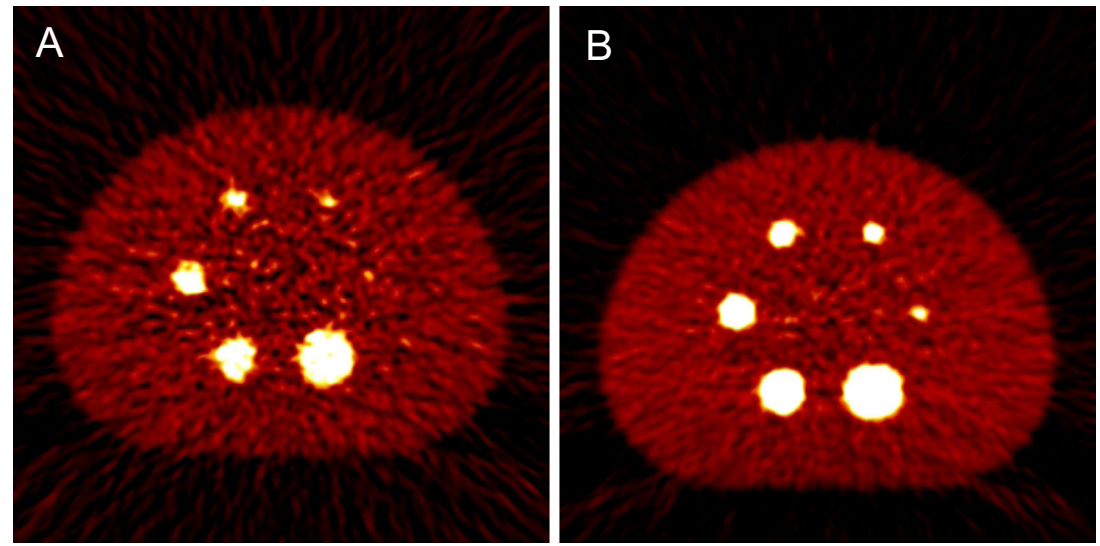
biologically relevant $t_{1 / 2}$, and absence of $\alpha$-emitting daughters. Auger electron emitting radionuclides that could be used as theranostic agents are gallium- $67\left({ }^{67} \mathrm{Ga}\right)$, bromine- $80 \mathrm{~m}$ $\left({ }^{80 \mathrm{~m}} \mathrm{Br}\right),{ }^{89} \mathrm{Zr}$, niobium-90 $\left({ }^{90} \mathrm{Nb}\right)$, technetium-99m $\left({ }^{99 \mathrm{~m}} \mathrm{Tc}\right)$, indium-111 ( $\left.{ }^{111} \mathrm{In}\right)$, tin-117m $\left({ }^{117 \mathrm{~m}} \mathrm{Sn}\right)$, antimony-119 $\left({ }^{119} \mathrm{Sb}\right)$, iodine-123 $\left({ }^{123} \mathrm{I}\right)$, iodine-125 $\left({ }^{125} \mathrm{I}\right)$, platinum- $195 \mathrm{~m}$ $\left({ }^{195 \mathrm{~m}} \mathrm{Pt}\right)$, and thallium-201 $\left({ }^{201} \mathrm{Tl}\right)$.

Intranuclear delivery of Auger electron-emitting constructs results in relative biological efficacy similar to that of $\alpha$ emitters but with a comparatively reduced crossfire effect, making them more suitable for single-cell irradiation than the $\alpha$ emitters. Auger electron emitters such as ${ }^{125} \mathrm{I}$ have a high linear energy transfer and short range of emission $(<10 \mu \mathrm{m})$, making them suitable for treating micrometastases while sparing normal tissues [38-40, 46, 47]. In addition, the radiation emitted during the nuclear decay can be used for imaging either using SPECT with $\gamma$ rays or Bremsstrahlung photons or PET, thereby rendering Auger-electron-emitting radionuclides as ideal theragnosis agents [48, 49]. Kiess's group at John's Hopkins University, used a highly specific small molecule targeting the prostate-specific membrane antigen to deliver ${ }^{125}$ I to prostate cancer cells [46]. Hasegawa's group at the National Institute of Radiological Science, Japan, reported that ${ }^{111}$ In trastuzumab modified with nuclear-localizing signal peptides efficiently delivered an Auger electron emitter ${ }^{111}$ In into the cell nucleus and, therefore, is a promising radiopharmaceutical in Auger electron RIT suitable for targeted killing of HER2-positive cancer cells [39].

Falzone's group at the University of Oxford, UK evaluated the characteristics of Auger electrons in terms of S values, the effect of cellular geometry and eccentric cell or nucleus arrangements on S values, dose-point kernels (DPKs), and energy deposition on a DNA scale compared with an $\alpha$ emitter, ${ }^{223} \mathrm{Ra}$. The DPK of ${ }^{223} \mathrm{Ra}$ and the Auger electron emitters showed that with respect to the energy deposited in spheres of DNA dimensions, only the higher-mass-number Auger electron emitters deposited comparable amounts of energy. However, compared with a mono-energetic 5.77-MeV $\alpha$ particle, the major advantage of Auger electron emitters is that they have a range of less than $11 \mathrm{~nm}[48,50]$.

\section{Macro-Level and Microcellular-Level Dosimetry}

The absorption of energy from ionizing radiation can cause damage to living tissues, and this effect is used as an advantage in radionuclide therapy. One of the most important factors in the assessment of the effects of radiation on an organ is the amount of radiation energy deposited in that organ. The calculation of radiation energy deposited by internal radionuclides is the focus of internal radiation dosimetry. Currently, whole-body dosimetry was used for RIT, and has proven to be a reliable method for determining the patient-specific maximally tolerated therapeutic radiation dose required to maximize efficacy while minimizing organ and bone marrow toxicity $[51,52]$. The Medical Internal Radiation Dosimetry (MIRD) formulation assumed that radioactivity and energy was uniformly distributed and deposited within each organ. This assumption can cause significant errors in the calculated dose as a result of nonpenetrating radiation (e.g., Auger electrons) when the activity was taken up in specific regions or cell types within an organ. Therefore, local radionuclide concentrations and the subsequently absorbed dose can be much higher than average calculations of quantities absorbed by organs might suggest [51]. Dewaraja et al. [53] developed the patient-specific, three-dimensional (3D) method for absorbed dose calculation. Although the mean dose estimates are quite adequate for diagnostic applications, greater accuracy is required for therapeutic applications and patient-specific $3 \mathrm{D}$ calculations. With the $3 \mathrm{D}$ dosimetry, the minimum and maximum doses, as well as dose nonuniformity can be estimated. Jin Su Kim's group in KIRAMS, Korea, performed imaging and therapy using ${ }^{131}$ I trastuzumab and a pinhole collimator attached to a conventional gamma camera for human use in a mouse model. Mouse dosimetry and prediction of human dosimetry could be used to provide data for the safety and efficacy of newly developed therapeutic schemes [54]. Meredith et al. [55] reported the first use of dosimetry in human $\alpha$ emitter labeled RIT with ${ }^{212} \mathrm{~Pb}$ TCMC-trastuzumab. Tools are needed to visualize and quantify the radioactivity distribution and absorbed doses to targeted and non-targeted cells for accurate dosimetry when $\alpha$-emitter-labeled RIT was performed [56]. Recently, a single-particle digital autoradiography named $\alpha$ camera was developed for the quantification of $\alpha$ particle for targeted radionuclide therapy. Miller et al. $[56,57]$ developed an $\alpha$ camera called the iQID camera, which is a scintillator-based radiation detection system that images and identifies $\alpha$ particle emissions spatially and temporally using CCD-CMOS cameras and high-performance computing hardware. The iQID camera technique was used for the quantitative imaging of ${ }^{211} \mathrm{At}$ activity distributions in cryosections of mouse and dog tissue samples [56]. Figure 2. shows the distribution of ${ }^{211}$ At $1 F 5$ (anti CD20 mAb) in the mouse kidney. Frost et al. [58] reported the result of using ${ }^{211}$ At localization and small-scale dosimetry for optimizing the $\mathrm{mAb}$ dose for ${ }^{211} \mathrm{At}$ RIT using $\alpha$-imaging systems.

\section{Limited Transport of mAb into Tumor}

RIT remains a challenge because of the limited delivery of $\mathrm{mAb}$ into tumors. The transport and uptake of $\mathrm{mAb}$ into tumors is slow and heterogeneous [59]. Although, a large amount of $\mathrm{mAb}$ intravenously injected, very little reaches the tumor and a large portion remains circulating in the plasma or is taken up even in normal tissues, thereby irradiating and killing healthy cells over time [60]. Uptaken and penetrated $\mathrm{mAb}$ was not evenly distributed within the tissue. Monoclonal 


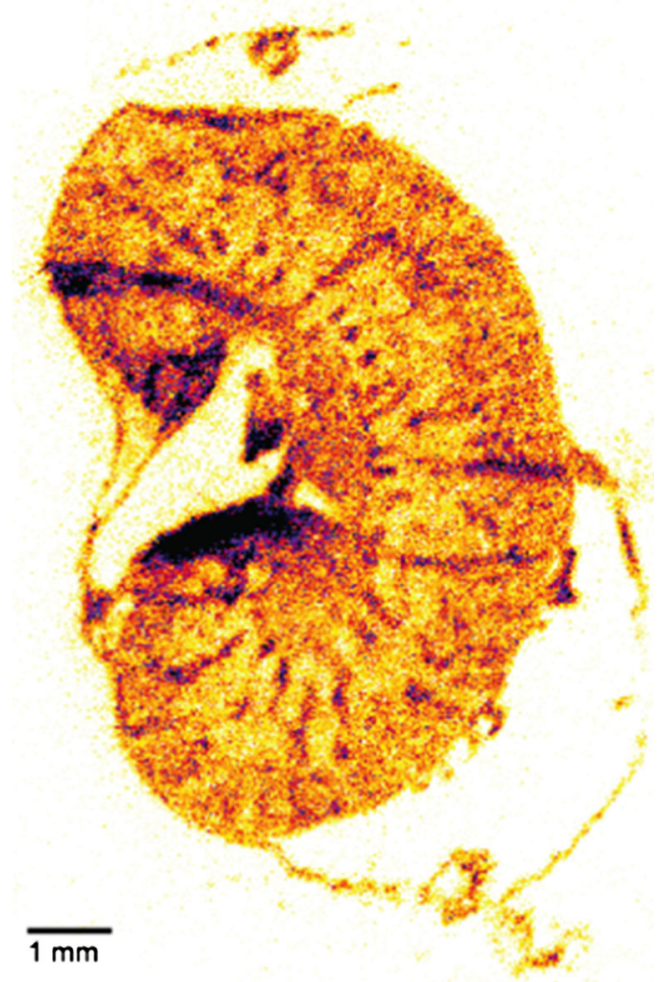

Fig. $2{ }^{211}$ At-1F5 (anti-CD20 mAb) micro-biodistribution for the mouse which was acquired using an $\alpha$ camera. This figure was reprinted from Miller et al. [56]

antibodies bind to their targets much faster than they diffuse through tissue [61]. Only cells adjacent to blood vessels was more targeted even in well-vascularized regions [62]. The steps associated with targeting $\mathrm{mAb}$ to tumors are blood flow to the tumor, extravasation across the blood vessel wall, diffusion into the tissue, and binding to the target [61]. Blood flow occurs in the order of minutes, while binding is completed in several seconds. While the rates of these processes can significantly affect the distribution of the $\mathrm{mAb}$ in the tumor, but they do not all have a major impact on the total amount localized in the tissue [61]. Extravasation across the blood vessel wall is the rate-limiting step in uptake. Monoclonal antibodies are transported into tumors by convection and diffusion. Convection of materials in fluids such as $\mathrm{mAb}$ in a tumor occurs by the movement of that liquid. This flow occurs when there is a difference in pressure, which forces the fluid from an area of high pressure to that of low pressure. Diffusion occurs as a result of the random Brownian motion of molecules in a liquid. The distance of $\mathrm{mAb}$ diffusion is proportional to the square root of time [59, 62-64].

The time required to deliver $\mathrm{mAbs}$ to the tumor vasculature can be calculated by measuring the blood flow. The time for blood flow can be calculated as follows

Blood flow time $=1 / Q(1-\mathrm{Ht})$ where $Q$ is the flow rate of the blood in the tumor (volume of whole blood per volume of tumor per time), and $H t$ is the hematocrit. The extravasation rate of $\mathrm{mAb}$ is very slow compared with measured flow rates and, therefore, the permeability typically has a greater impact on the uptake [60].

The time it takes for the mAbs to penetrate a specified volume of a tumor is calculated as:

Extravasation time $=V / P S$

where $P$ is the permeability and $S / V$ is the blood vessel surface area to tumor volume ratio [60].

Convection within the tissue are small compared with the rate of diffusion and, therefore, diffusive movement mainly drives the interstitial transport. Using Fick's law, diffusion time is calculated as:

$\mathrm{D} \approx \mathrm{R}^{2} / \mathrm{D} \varepsilon$

where $R$ is the distance the mAb must diffuse, $D$ is the diffusion coefficient between the cells, and $\varepsilon$ is the void fraction [60].

Extravasation and diffusion were limiting step for delivery of mAbs. According to the mathematical analysis, estimated permeability in step of extravasation was $0.003 \mu \mathrm{m} / \mathrm{s}$ for $\mathrm{mAb}$ and $1 \mu \mathrm{m} / \mathrm{s}$ for FDG and diffusion rate was $10 \mu \mathrm{m}^{2} / \mathrm{s}$ for $\mathrm{mAb}$ and $500 \mu \mathrm{m}^{2} / \mathrm{s}$ for FDG [64]. The estimated time-based mathematical analysis for delivering the mAb to the tumor was $10 \mathrm{~min}$ for convection, $18 \mathrm{~h}$ for extravasation, $24 \mathrm{~min}$ for diffusion, and $12 \mathrm{~s}$ for binding [59, 60, 64].

\section{Enhancement of mAb Penetration into Tumor}

The tumor microenvironment contributed to the limited delivery of the mAb [65]. The limited targeting and insufficient dose delivery of $\mathrm{mAb}$ to solid tumor were caused by abnormal structure of tumor vessel, highly fibrotic or desmoplastic tumor, absence of functional lymphatics, and high fluid permeability [59, 66-68]. Tumor cells are surrounded by layers of extracellular matrix (ECM) proteins (e.g., collagen, elastin, fibronectin, and laminin), which largely prevents the tumor vasculature from penetrating the tumor nests. Tumor-derived ECM plays an important role in inhibiting the penetration and dispersion of cancer therapeutic agents within tumor masses and has been implicated in the resistance of solid tumors to therapy [69]. Beyer et al. [69] observed extensive tumor ECM and intercellular junctions in patients with breast cancer and in xenograft models [70].

Targeting tumors with mAb-based therapeutics is a complex task that presents multiple kinetic barriers. Monoclonal antibody internalization and clearance inhibit uptake both in solid tumors limited by tumor vascular permeability and in micrometastases limited by diffusion $[61,69]$. To improve the 
efficacy of RIT, binding-site barriers need to be surmounted to enhance the distribution of mAb uniformly in tumors. The binding-site barriers can cause non-uniform distribution of $\mathrm{mAb}$ in the tumor microenvironment because radiolabeled mAbs bind primarily to the tumor cells nearest to the vasculature. This hinders the uniform distribution of radiolabeled mAbs throughout the tumor unless the dose of mAbs administered is at a concentration that can saturate all antigens on the tumor cells. Nonuniform microdistribution of $\mathrm{mAb}$ leads to a marked difference in individual cell survival across the tumor [71]. Therefore, although RIT was shown to be effective against hematological tumors, solid tumors were less responsive due to insufficient dose delivery and radiation resistance [72]. Numerous solutions such as fractionated dosing [73] and $\mathrm{mAb}$ pretargeting methods [74], as well as recombinant immunotoxins [75], were introduced in attempts to improve the efficacy of RIT against solid tumors. Yun's group at Hanynag University, Korea used ECM-degrading oncolytic adenovirus to achieve a desirable therapeutic outcome in pancreatic cancer [76]. Decorin modulates tumor ECM production and, therefore, has an integral role in the degradation or downregulation of tumor ECM constituents or both. The decorinbased approach would be effective for increasing mAb penetration into solid tumors $[69,77]$. Chang H. Paik's group at NIH, USA used paclitaxel (Taxol) [8] or pulsed high-intensity focused ultrasound to enhance the therapeutic efficacy of RIT against solid tumors [9, 78]. Furthermore, combined RIT strategies could be used to cure solid tumors in patients if the accumulation and penetration of $\mathrm{mAb}$ into the tumor microenvironment could be increased, thereby sensitizing more tumor cells to the radiation from the radiolabeled $\mathrm{mAb}$.

Regarding microcellular level imaging of $\mathrm{mAb}$ distribution, microcellular level studies by Paik et al. [8, 9] showed the penetration and enhanced accumulation of mAbs in tumors following the modulation of the tumor microenvironment $[9,78]$. Although conventional clinical nuclear medicine imaging techniques such as PET and SPECT have been widely used in molecular imaging, they have limited spatial resolution for revealing the intratumoral $\mathrm{mAb}$ micro-distribution. Therefore, imaging of fluorescent dye-conjugated $\mathrm{mAb}$ distribution would be useful to confirm the micro-distribution of mAbs within tumors.

\section{Conclusion}

The tumor microenvironment may play an important role in solid tumor RIT. When $\alpha$-emitter-labeled mAbs were used, deeper penetration of $\alpha$-emitter-labeled mAbs inside tumors was more important because of the short range of the $\alpha$ emitter. Moreover, combination therapy strategies aimed at improving $\mathrm{mAb}$ tumor penetration and accumulation are crucial and would be beneficial for maximizing their therapeutic efficacy against solid tumors.

Acknowledgments This work was supported by the Korea Science and Engineering Foundation (KOSEF) (No. 2015001667 [P.I., Joo Hyun Kang]), No. 1711026888 [P.I., Kook-Hyun Yu]), and Heath technology R\&D (No HO15C0003 [P.I., JIN SU KIM]).

\section{Compliance with Ethical Standards}

Conflict of Interest Jin Su Kim have no conflict of interests.

Ethical Statement This article does not contain any studies with human participants or animals performed by any of the authors. The study was approved by an institutional review board or equivalent and has been performed in accordance with the ethical standards laid down in the 1964 Declaration of Helsinki and its later amendments. All subjects in the study gave written informed consent or the institutional review board waived the need to obtain informed consent.

Disclosure This manuscript has not been published before or is not under consideration for publication anywhere else.

Open Access This article is distributed under the terms of the Creative Commons Attribution 4.0 International License (http:// creativecommons.org/licenses/by/4.0/), which permits unrestricted use, distribution, and reproduction in any medium, provided you give appropriate credit to the original author(s) and the source, provide a link to the Creative Commons license, and indicate if changes were made.

\section{References}

1. Erdi AK, Erdi YE, Yorke ED, Wessels BW. Treatment planning for radio-immunotherapy. Phys Med Biol. 1996;41:2009-26.

2. Allen TM. Ligand-targeted therapeutics in anticancer therapy. Nat Rev Cancer. 2002;2:750-63.

3. Larson SM, Carrasquillo JA, Cheung NK, Press OW. Radioimmunotherapy of human tumours. Nat Rev Cancer. 2015;15:347-60.

4. Gopal AK, Gooley TA, Rajendran JG, Pagel JM, Fisher DR, Maloney DG, et al. Myeloablative ${ }^{131}$ I-tositumomab with escalating doses of fludarabine and autologous hematopoietic transplantation for adults age $\geq 60$ years with B cell lymphoma. Biol Blood Marrow Transplant. 2014;206:770-5.

5. Becker W, Behr T. High dose radioimmunotherapy in relapsed Bcell lymphoma with ${ }^{131}$ I-rituximab. Ann Hematol. 2001;80 Suppl 3:B130-1.

6. Kang GW, Kang HJ, Shin DY, Gu HR, Choi HS, Lim SM. Radioimmunotherapy with ${ }^{131}$ I-rituximab in a patient with diffuse large B-cell lymphoma relapsed after treatment with ${ }^{90} \mathrm{Y}$ Ibritumomab tiuxetan. Nucl Med Mol Imaging. 2013;47:281-4.

7. Zalutsky MR, Pozzi OR. Radioimmunotherapy with alpha-particle emitting radionuclides. Q J Nucl Med Mol Imaging. 2004;48:28996.

8. Jang BS, Lee SM, Kim HS, Shin IS, Razjouyan F, Wang S, et al. Combined-modality radioimmunotherapy: synergistic effect of paclitaxel and additive effect of bevacizumab. Nucl Med Biol. 2012;39:472-83.

9. Wang S, Shin IS, Hancock H, Jang BS, Kim HS, Lee SM, et al. Pulsed high intensity focused ultrasound increases penetration and 
therapeutic efficacy of monoclonal antibodies in murine xenograft tumors. J Control Release. 2012;20(162):218-24.

10. Boerman OC, Oyen WJ. Immuno PET of cancer: a revival of antibody imaging. J Nucl Med. 2011;52:1171-2.

11. van Dongen GA, Visser GW, Lub-de Hooge MN, de Vries EG, Perk LR. Immuno PET: a navigator in monoclonal antibody development and applications. Oncologist. 2007;12:1379-89.

12. Deri MA, Zeglis BM, Francesconi LC, Lewis JS. PET imaging with ${ }^{89} \mathrm{Zr}$ : from radiochemistry to the clinic. Nucl Med Biol. 2013;40:314.

13. Tamura K, Kurihara H, Yonemori K, Tsuda H, Suzuki J, Kono Y, et al. ${ }^{64} \mathrm{Cu}$ DOTA-trastuzumab PET imaging in patients with HER2-positive breast cancer. J Nucl Med. 2013;54:1869-75.

14. Mortimer JE, Bading JR, Colcher DM, Conti PS, Frankel PH, Carroll MI, et al. Functional imaging of human epidermal growth factor receptor 2-positive metastatic breast cancer using ${ }^{64} \mathrm{Cu}$ DOTA-trastuzumab PET. J Nucl Med. 2014;55:23-9.

15. Braghirolli AM, Waissmann W, da Silva JB, dos Santos GR. Production of ${ }^{124} \mathrm{I}$ and its applications in nuclear medicine. Appl Radiat Isot. 2014;90:138-48

16. Preylowski V, Schlogl S, Schoenahl F, Jorg G, Samnick S, Buck $\mathrm{AK}$, et al. Is the image quality of ${ }^{124}$ I PET impaired by an automatic correction of prompt gammas? PLoS One. 2013;27(8):e71729.

17. Lee YS, Kim JS, Kim H-J, Woo S-K, Kim JG, Park JA, et al Imaging Characteristics of ${ }^{124}$ I Between 3D and 2D on Siemens ECAT HR PET Scanner. IEEE Trans Nucl Sci. 2013;60:797-801.

18. Kim JS, Yu AR. Determination of single gamma photon fraction of ${ }^{124}$ I PET. J Instrum. 2015;10(P03006):1-8.

19. Yu AR, Kim JS. Effect of filters and reconstruction algorithms on ${ }^{124}$ I PET in Siemens Inveon PET scanner. J Instrum. 2015;10(P10026):1-12

20. Yu AR, Kim JS, Kang JH, Lim SM. Comparison of reconstruction methods and quantitative accuracy in Siemens Inveon PET scanner. J Instrum. 2015;10(P04001):1-16.

21. Vosjan MJ, Perk LR, Visser GW, Budde M, Jurek P, Kiefer GE, et al. Conjugation and radiolabeling of monoclonal antibodies with ${ }^{89} \mathrm{Zr}$ for PET imaging using the bifunctional chelate pisothiocyanatobenzyl-desferrioxamine. Nat Protoc. 2010;5:739-43.

22. Borjesson PK, Jauw YW, Boellaard R, de Bree R, Comans EF, Roos JC, et al. Performance of immuno PET with ${ }^{89} \mathrm{Zr}$ chimeric mAb U36 in the detection of lymph node metastases in head and neck cancer patients. Clin Cancer Res. 2006;12:2133-40.

23. Sugyo A, Tsuji AB, Sudo H, Nagatsu K, Koizumi M, Ukai Y, et al. Evaluation of ${ }^{89} \mathrm{Zr}$ labeled human anti-CD147 $\mathrm{mAb}$ as a PET probe in a mouse model of pancreatic cancer. PLoS One. 2013;8:e61230.

24. Lee YS, Kim JS, Kim JY, Kim BI, Lim SM, Kim HJ. Spatial resolution and image qualities of ${ }^{89} \mathrm{Zr}$ on Siemens Biograph TruePoint PET/CT. Cancer Biother Radiopharm. 2015;30:27-32.

25. Disselhorst JA, Brom M, Laverman P, Slump CH, Boerman OC, Oyen WJ, et al. Image-quality assessment for several positron emitters using the NEMA NU 4-2008 standards in the Siemens Inveon small-animal PET scanner. J Nucl Med. 2010;51:610-7.

26. Quackenbush RC, Horner TJ, Williams VC, Giampietro P, Lin TS. Patients with relapsed follicular lymphoma treated with rituximab versus tositumomab and ${ }^{131} \mathrm{I}$ tositumomab. Leuk Lymphoma. 2015;56:779-81.

27. Srinivasan A, Mukherji SK. Tositumomab and ${ }^{131}$ I tositumomab (Bexaar). AJNR Am J Neuroradiol. 2011;32:637-8.

28. Sjogreen-Gleisner K, Dewaraja YK, Chiesa C, Tennvall J, Linden $\mathrm{O}$, Strand SE, et al. Dosimetry in patients with B-cell lymphoma treated with ${ }^{90} \mathrm{Y}$ ibritumomab tiuxetan or ${ }^{131}$ I tositumomab. Q J Nucl Med Mol Imaging. 2011;55:126-54.

29. Hohloch K, Lankeit HK, Zinzani PL, Scholz CW, Lorsbach M, Windemuth-Kieselbach $\mathrm{C}$, et al. Radioimmunotherapy for firstline and relapse treatment of aggressive B-cell non-Hodgkin lymphoma: an analysis of 215 patients registered in the international RIT-Network. Eur J Nucl Med Mol Imaging. 2014;41:1585-92.

30. Andrade Campos MM, Montes Limon AE, Grasa JM, Lievano P, Baringo T, Giraldo P. RIT with ${ }^{90}$ Y-ibritumomab tiuxetan in follicular non-Hodgkin lymphoma: evaluation of recent outcomes in a single institution. J Oncol. 2012;2012:412742.

31. Prasad V. The withdrawal of drugs for commercial reasons: the incomplete story of tositumomab. JAMA Intern Med. 2014;174: $1887-8$.

32. Frost SH, Frayo SL, Miller BW, Orozco JJ, Booth GC, Hylarides $\mathrm{MD}$, et al. Comparative efficacy of ${ }^{177} \mathrm{Lu}$ and ${ }^{90} \mathrm{Y}$ for anti-CD20 pretargeted radioimmunotherapy in murine lymphoma xenograft models. PLoS One. 2015;18(10):e0120561.

33. Attarwala AA, Molina-Duran F, Busing KA, Schonberg SO, Bailey DL, Willowson K, et al. Quantitative and qualitative assessment of ${ }^{90}$ Y PET/CT imaging. PLoS One. 2014;4(9):e110401.

34. Lhommel R, Goffette P, Van den Eynde M, Jamar F, Pauwels S, Bilbao JI, et al. ${ }^{90} \mathrm{Y}$ TOF PET scan demonstrates high-resolution biodistribution after liver SIRT. Eur J Nucl Med Mol Imaging. 2009;36:1696.

35. Rong X, Du Y, Frey EC. A method for energy window optimization for quantitative tasks that includes the effects of model-mismatch on bias: application to ${ }^{90} \mathrm{Y}$ bremsstrahlung SPECT imaging. Phys Med Biol. 2012;21(57):3711-25.

36. de Jong M, Breeman WA, Valkema R, Bernard BF, Krenning EP. Combination radionuclide therapy using ${ }^{177} \mathrm{Lu}$ and ${ }^{90} \mathrm{Y}$ labeled somatostatin analogs. J Nucl Med. 2005;46 Suppl 1:13S-7.

37. Siegel JA, Stabin MG. Absorbed fractions for electrons and beta particles in spheres of various sizes. J Nucl Med. 1994;35:152-6.

38. Lu Y, Ndjock N, Mbong G, Liu P, Chan C, Cai Z, et al. Synthesis of polyglutamide-based metal-chelating polymers and their sitespecific conjugation to trastuzumab for auger electron radioimmunotherapy. Biomacromolecules. 2014;9(15):2027-37.

39. Li HK, Morokoshi Y, Daino K, Furukawa T, Kamada T, Saga T, et al. Transcriptomic signatures of auger electron radioimmunotherapy using nuclear targeting ${ }^{111}$ In-trastuzumab for potential combination therapies. Cancer Biother Radiopharm. 2015;30:349-58.

40. Baranowska-Kortylewicz J. Intraperitoneal radioimmunotherapy: Auger electron emitters for solid tumors. Immunotherapy. 2011;3: 491-4.

41. Pfost B, Seidl C, Autenrieth M, Saur D, Bruchertseifer F, Morgenstern A, et al. Intravesical alpha-radioimmunotherapy with ${ }^{213} \mathrm{Bi}$ anti-EGFR-mAb defeats human bladder carcinoma in xenografted nude mice. J Nucl Med. 2009;50:1700-8.

42. Back T, Haraldsson B, Hultborn R, Jensen H, Johansson ME, Lindegren $\mathrm{S}$, et al. Glomerular filtration rate after alpharadioimmunotherapy with ${ }^{211}$ At MX35-F(ab')2: a long-term study of renal function in nude mice. Cancer Biother Radiopharm. 2009;24:649-58.

43. Lucignani G. Alpha-particle radioimmunotherapy with ${ }^{211}$ At and ${ }^{213} \mathrm{Bi}$. Eur J Nucl Med Mol Imaging. 2008;35:1729-33.

44. Zhang M, Yao Z, Zhang Z, Garmestani K, Talanov VS, Plascjak PS, et al. The anti-CD25 monoclonal antibody 7G7/B6, armed with the alpha-emitter ${ }^{211} \mathrm{At}$, provides effective radioimmunotherapy for a murine model of leukemia. Cancer Res. 2006;66:8227-32.

45. Song H, Hobbs RF, Vajravelu R, Huso DL, Esaias C, Apostolidis C, et al. Radioimmunotherapy of breast cancer metastases with alphaparticle emitter ${ }^{225} \mathrm{Ac}$ : comparing efficacy with ${ }^{213} \mathrm{Bi}$ and ${ }^{90} \mathrm{Y}$. Cancer Res. 2009;69:8941-8.

46. Kiess AP, Minn I, Chen Y, Hobbs R, Sgouros G, Mease RC, et al. Auger radiopharmaceutical therapy targeting prostate-specific membrane antigen. J Nucl Med. 2015;56:1401-7.

47. Gardette M, Viallard C, Paillas S, Guerquin-Kern JL, Papon J, Moins N, et al. Evaluation of two ${ }^{125} \mathrm{I}$ radiolabeled acridine 
derivatives for Auger-electron radionuclide therapy of melanoma. Investig New Drugs. 2014;32:587-97.

48. Falzone N, Fernandez-Varea JM, Flux G, Vallis KA. Monte Carlo evaluation of auger electron-emitting theranostic radionuclides. J Nucl Med. 2015;56:1441-6.

49. Kelkar SS, Reineke TM. Theranostics: combining imaging and therapy. Bioconjug Chem. 2011;19(22):1879-903.

50. Charlton DE. The range of high LET effects from ${ }^{125} \mathrm{I}$ decays. Radiat Res. 1986;107:163-71.

51. Dewaraja YK, Frey EC, Sgouros G, Brill AB, Roberson P, Zanzonico PB, et al. MIRD pamphlet No. 23: quantitative SPECT for patient-specific 3-dimensional dosimetry in internal radionuclide therapy. J Nucl Med. 2012;53:1310-25.

52. Wahl RL. The clinical importance of dosimetry in radioimmunotherapy with tositumomab and ${ }^{131}$ I tositumomab. Semin Oncol. 2003;30:31-8.

53. Dewaraja YK, Wilderman SJ, Ljungberg M, Koral KF, Zasadny K, Kaminiski MS. Accurate dosimetry in ${ }^{131}$ I radionuclide therapy using patient-specific, 3-dimensional methods for SPECT reconstruction and absorbed dose calculation. J Nucl Med. 2005;46: $840-9$.

54. Lee YS, Kim JS, Cho KD, Kang JH, Lim SM. Tumor dosimetry for ${ }^{131}$ I trastuzumab therapy in a Her2+ NCI N87 xenograft mouse model using the Siemens SYMBIA E gamma camera with a pinhole collimator. J Instrum. 2015;10(P07001):1-10.

55. Meredith R, Torgue J, Shen S, Fisher DR, Banaga E, Bunch P, et al. Dose escalation and dosimetry of first-in-human alpha radioimmunotherapy with ${ }^{212} \mathrm{~Pb}$ TCMC-trastuzumab. J Nucl Med. 2014;55:1636- 42.

56. Miller BW, Frost SH, Frayo SL, Kenoyer AL, Santos E, Jones JC, et al. Quantitative single-particle digital autoradiography with alpha-particle emitters for targeted radionuclide therapy using the iQID camera. Med Phys. 2015;42:4094-105.

57. Miller BW, Gregory SJ, Fuller ES, Barrett HH, Barber HB, Furenlid LR. The iQID camera: an ionizing-radiation quantum imaging detector. Nucl Instrum Methods Phys Res Sect A. 2014;11(767):14652.

58. Frost SH, Miller BW, Back TA, Santos EB, Hamlin DK, Knoblaugh SE, et al. Alpha imaging confirmed efficient targeting of CD45-positive cells after ${ }^{211}$ At radioimmunotherapy for hematopoietic cell transplantation. J Nucl Med. 2015;56:1766-73.

59. Thurber GM, Schmidt MM, Wittrup KD. Factors determining antibody distribution in tumors. Trends Pharmacol Sci. 2008;29:5761.

60. Thurber GM, Schmidt MM, Wittrup KD. Antibody tumor penetration: transport opposed by systemic and antigen-mediated clearance. Adv Drug Deliv Rev. 2008;60:1421-34.

61. Thurber GM, Zajic SC, Wittrup KD. Theoretic criteria for antibody penetration into solid tumors and micrometastases. J Nucl Med. 2007;48:995-9.

62. Thurber GM, Weissleder R. Quantitating antibody uptake in vivo: conditional dependence on antigen expression levels. Mol Imaging Biol. 2011;13:623-32.
63. Thurber GM, Dane Wittrup K. A mechanistic compartmental model for total antibody uptake in tumors. J Theor Biol. 2012;314:5768 .

64. Thurber GM, Weissleder R. A systems approach for tumor pharmacokinetics. PLoS One. 2011;6:e24696.

65. Tredan O, Galmarini CM, Patel K, Tannock IF. Drug resistance and the solid tumor microenvironment. J Natl Cancer Inst. 2007;99: 1441-54.

66. Jain RK, Stylianopoulos T. Delivering nanomedicine to solid tumors. Nat Rev Clin Oncol. 2010;7:653-64.

67. Heldin $\mathrm{CH}$, Rubin K, Pietras K, Ostman A. High interstitial fluid pressure - an obstacle in cancer therapy. Nat Rev Cancer. 2004;4: 806-13.

68. Heine M, Freund B, Nielsen P, Jung C, Reimer R, Hohenberg H, et al. High interstitial fluid pressure is associated with low tumour penetration of diagnostic monoclonal antibodies applied for molecular imaging purposes. PLoS One. 2012;7:e36258.

69. Choi IK, Strauss R, Richter M, Yun CO, Lieber A. Strategies to increase drug penetration in solid tumors. Front Oncol. 2013;26(3): 193.

70. Beyer I, Li Z, Persson J, Liu Y, van Rensburg R, Yumul R, et al. Controlled extracellular matrix degradation in breast cancer tumors improves therapy by trastuzumab. Mol Ther. 2011;19:479-89.

71. Du Y, Honeychurch J, Glennie M, Johnson P, Illidge T. Microscopic intratumoral dosimetry of radiolabeled antibodies is a critical determinant of successful radioimmunotherapy in B-cell lymphoma. Cancer Res. 2007;67:1335-43.

72. Jhanwar YS, Divgi C. Current status of therapy of solid tumors. J Nucl Med. 2005;46 Suppl 1:141S-50.

73. Ocean AJ, Pennington KL, Guarino MJ, Sheikh A, Bekaii-Saab T, Serafini AN, et al. Fractionated radioimmunotherapy with ${ }^{90} \mathrm{Y}$ clivatuzumab tetraxetan and low-dose gemcitabine is active in advanced pancreatic cancer: a phase 1 trial. Cancer. 2012;118:5497506.

74. Goldenberg DM, Sharkey RM, Paganelli G, Barbet J, Chatal JF. Antibody pretargeting advances cancer radioimmunodetection and radioimmunotherapy. J Clin Oncol. 2006;24:823-34.

75. Weldon JE, Xiang L, Zhang J, Beers R, Walker DA, Onda M, et al. A recombinant immunotoxin against the tumor-associated antigen mesothelin reengineered for high activity, low off-target toxicity, and reduced antigenicity. Mol Cancer Ther. 2013;12:48-57.

76. Na Y, Choi JW, Kasala D, Hong J, Oh E, Li Y, et al. Potent antitumor effect of neurotensin receptor-targeted oncolytic adenovirus co-expressing decorin and Wnt antagonist in an orthotopic pancreatic tumor model. J Control Release. 2015;220(Pt B):766-82.

77. Vogel KG, Paulsson M, Heinegard D. Specific inhibition of type I and type II collagen fibrillogenesis by the small proteoglycan of tendon. Biochem J. 1984;223:587-97.

78. Khaibullina A, Jang BS, Sun H, Le N, Yu S, Frenkel V, et al. Pulsed high-intensity focused ultrasound enhances uptake of radiolabeled monoclonal antibody to human epidermoid tumor in nude mice. J Nucl Med. 2008;49:295-302. 